\title{
EFEITOS DA ENZIMA $\beta$-MANANASE SOBRE A MORFOMETRIA INTESTINAL E O DESEMPENHO DE PERUS NA FASE INICIAL
}

\section{(Effects of the enzyme $\beta$-mannanase on the intestinal morphology and performance of 21 days old turkeys)}

\author{
Rafael Fernando Sens ${ }^{1}$, Leopoldo Malcorra de Almeida ${ }^{1}$, Lucas Schmidt Bassi ${ }^{1}$, Josiane Carla \\ Panisson ${ }^{1}$, Alex Maiorca ${ }^{1}$, Simone Gisele de Oliveira ${ }^{1}$ \\ ${ }^{1}$ Universidade Federal do Paraná, Curitiba, Paraná, Brasil
}

Corresponding author: rafael.f.sens@gmail.com

RESUMO: Em muitos ingredientes utilizados na alimentação de perus, estão presentes compostos conhecidos como $\beta$-mananos, polissacarídeos não amiláceos que comprometem o aproveitamento dos nutrientes da dieta. $\mathrm{O}$ objetivo do presente experimento foi avaliar os efeitos da enzima $\beta$-mananase em dietas para peruas sobre a altura de vilos e a profundidade das criptas, aos 7 dias, e o desempenho zootécnico, aos 7 e 21 dias de idade. Foram utilizadas 432 aves, distribuídas em delineamento experimental inteiramente ao acaso composto por três tratamentos: T1 - dieta basal; T2: dieta basal com redução de $150 \mathrm{kcal} / \mathrm{kg}$ e; T3: dieta basal com redução de $150 \mathrm{kcal} / \mathrm{kg}$ + adição da enzima $\beta$-mananase. Os dados obtidos foram submetidos à análise de variância $e$, no caso de diferenças significativas, comparadas estatisticamente pelo teste de Duncan (5\%). A adição da enzima $\beta$ mananase permitiu reduzir os níveis de energia da dieta sem que fossem afetadas a altura de vilos e profundidade de criptas, aos 7 dias de idade, bem como melhorou o ganho de peso na fase inicial ( 1 aos 21 dias de idade).

Palavras-chave: Vilosidades, farelo de soja, fatores antinutricionais, polissacarídeos não amiláceos.

ABSTRACT: Many ingredients used in feed for turkeys contain compounds known as $\beta$-mannanas, non-starch polysaccharides that compromise the utilization of nutrients from the diet. The objective of this experiment was to evaluate the effects of the enzyme $\beta$-mannanase in diets for turkeys on the height of villi and depth of crypts at 7 days, and performance at 7 and 21 days. 432 birds were distributed in a fully randomized experimental design with 3 treatments: T1 - basal diet; T2: basal diet with reduction of $150 \mathrm{kcal} / \mathrm{kg}$ and; T3: basal diet with reduction of $150 \mathrm{kcal} / \mathrm{kg}$ + addition of the enzyme $\beta$-mannanase. All data were submitted to analysis of variance and in case of significant differences, means were compared statistically by Duncan test (5\%). The addition of the enzyme $\beta$-mannanase allowed for a reduction of dietary energy levels without compromising villi height and depth of crypts at 7 days. In addition, $\beta$-mannanase improved body weight gain from 1 to 21 days.

Keywords: Antinutritional factors, non-starch polysaccharides, soybean meal, villosities. 


\section{INTRODUÇÃO}

A avicultura brasileira vem crescendo ao longo dos últimos anos, e a produção de perus claramente segue esta tendência. A alimentação se apresenta como o maior custo na produção destas aves, onde dietas de perus de corte têm como característica marcante a alta exigência protéica, especialmente na fase inicial (1 a 21 dias). Por isso, é comum que o farelo de soja, ingrediente consagrado por seu alto valor protéico, seja utilizado em abundância para que estas exigências sejam atendidas.

Em diversos ingredientes, como no próprio farelo de soja, estão presentes compostos conhecidos como $\beta$ mananos, reconhecidos como fatores antinutricionais (Hsiao et al., 2006; Verma et al., 1982) responsáveis por prejudicarem a absorção de diversos nutrientes da dieta (Choct, 2010). Chanzy e Voung (1985) classificam os $\beta$-mananos como polissacarídeos não amiláceos compostos por moléculas de $\beta-1-4$ manose, 1-6 galactose e glicose, ligadas a uma estrutura de $\beta$-mananos.

São compostos resistentes ao calor e, portanto, sobrevivem às fases de secagem e tostagem do processamento da soja (Dale, 1997). Compõe aproximadamente $1,3 \%$ do farelo de soja com $48 \%$ de proteína bruta e entre 1,5 e $1,7 \%$ do farelo de soja com $44 \%$ de proteína bruta. Vários experimentos mostram que os $\beta$ mananos atravessam a mucosa intestinal e potencializam o estímulo do sistema imunológico inato, aumentando a população de macrófagos e monócitos e resultando na produção de citocinas (Peng et al., 1991; Zhang e Tizzard, 1996; Ross et al., 2002).

Dietas com alto nível de $\beta$ mananos levam ainda à redução da retenção de nitrogênio, absorção de gordura e energia metabolizável (Kratzer et al., 1967), diminuição a taxa de absorção de glicose (Nunes \&
Malmlof, 1992), bem como da absorção de aminoácidos (Elsenhans et al., 1980).

O objetivo do presente experimento foi o de avaliar os efeitos da adição da enzima $\beta$-mananase em dietas de peruas de corte sobre a morfometria intestinal, aos 7 dias de idade, e o desempenho, aos 7 e 21 dias de idade.

\section{MATERIAL E MÉTODOS}

Para o experimento foram utilizadas 432 peruas de corte da linhagem BUT9, de um dia de idade, as quais foram alojadas em gaiolas metálicas com dimensões $0,98 \times 0,90 \times$ $0,50 \mathrm{~m}(\mathrm{C} \times \mathrm{L} \times \mathrm{H})$ e aquecidas individualmente por campânulas elétricas. As aves receberam ração e água a vontade por todo o período experimental. A sala onde as aves foram criadas possuía temperatura controlada, mantida ao primeiro dia à temperatura de $31^{\circ} \mathrm{C}$, sendo gradativamente reduzida até $22^{\circ} \mathrm{C}$.

As aves foram distribuídas em um delineamento experimental inteiramente casualizado em três tratamentos de oito repetições, com 18 aves cada. Os tratamentos foram divididos de acordo com o valor energético da dieta e a adição da enzima $\beta$-mananase da seguinte forma: T1 (dieta basal); T2 (dieta basal com redução de 150 $\mathrm{kcal} / \mathrm{kg}$ ) e T3 (deita basal com redução de $150 \mathrm{kcal} / \mathrm{kg}$ e adição de $\beta$ mananase).

As dietas experimentais foram peletizadas e trituradas, formuladas à base de milho e farelo de soja, de acordo com as recomendações propostas pelo manual da linhagem (Tabela 1). No tratamento três foram adicionados $110.000 \mathrm{UI}$ de $\beta$-mananase por kg de ração após o resfriamento por meio de aspersão.

No estudo de desempenho foram realizadas pesagens das aves e da 
ração no alojamento, aos 7 e 21 dias de idade para determinação do consumo de ração, ganho de peso e índice de conversão alimentar.

Tabela 1. Composição dos ingredientes e níveis nutricionais calculados das diferentes dietas experimentais fornecidas a peruas na fase inicial (1-21dias).

\begin{tabular}{|c|c|c|c|}
\hline Ingredientes (\%) & $\mathrm{T} 1^{1}$ & T2 & T3 \\
\hline Milho & 40,89 & 37,25 & 37,25 \\
\hline Farelo de Soja $46 \%$ & 43,53 & 46,48 & 46,48 \\
\hline Farinha de Soja Micronizada & 7 & 7 & 7 \\
\hline Fosfato Monobicálcico 20 \% & 2,76 & 2,76 & 2,76 \\
\hline Óleo de Soja Degomado & 2,5 & 1 & 1 \\
\hline Caulim & - & 2 & 1,98 \\
\hline Calcário Calcítico & 1,78 & 1,74 & 1,74 \\
\hline DI-Metionina & 0,33 & 0,33 & 0,33 \\
\hline L-Lisina & 0,3 & 0,27 & 0,27 \\
\hline Sal Moído & 0,45 & 0,45 & 0,45 \\
\hline Premix Mineral $^{2}$ & 0,1 & 0,1 & 0,1 \\
\hline Premix Vitamínico ${ }^{3}$ & 0,15 & 0,15 & 0,15 \\
\hline L-Treonina $98,5 \%$ & 0,14 & 0,13 & 0,13 \\
\hline Cloreto de Colina $60 \%$ & 0,04 & 0,04 & 0,04 \\
\hline$\beta$-Mananase & - & - & 0,02 \\
\hline $\begin{array}{r}\text { Nutrientes } \\
\end{array}$ & T1 & $\mathrm{T} 2$ & T3 \\
\hline Proteína Bruta & 27,5 & 27,5 & 27,5 \\
\hline $\mathrm{Ca}$ & 1,43 & 1,43 & 1,43 \\
\hline P Disponível & 0,75 & 0,75 & 0,75 \\
\hline Lisina (dig) & 1,6 & 1,6 & 1,6 \\
\hline Metionina (dig) & 0,7 & 0,7 & 0,7 \\
\hline Metionina + Cistina (dig) & 1,12 & 1,12 & 1,12 \\
\hline Treonina (dig) & 1,17 & 1,17 & 1,17 \\
\hline Triptofano (dig) & 0,34 & 0,34 & 0,34 \\
\hline Energia Metabolizável (kcal/kg) & 2.950 & 2.800 & 2.800 \\
\hline
\end{tabular}

${ }^{1}$ T1 - dieta basal; T2 - dieta basal com redução de $150 \mathrm{kcal} / \mathrm{kg} ; \mathrm{T} 3$ - dieta basal com redução de $150 \mathrm{kcal} / \mathrm{kg} \mathrm{e}$ adição de $\beta$-mananase.

${ }^{2}$ Fornecido por kg de ração: Cobre 20 mg, Ferro 50 mg, Manganês 115 mg, Zinco 100 mg, lodo 2 mg, Selênio $0,35 \mathrm{mg}$.

${ }^{3}$ Fornecido por kg de ração: Vitamina A 11.000 UI, Vitamina D3 3.600 UI, Vitamina E 55 mg, Vitamina K 4 mg, Vitamina B1 $3 \mathrm{mg}$, Vitamina B2 $10 \mathrm{mg}$, Vitamina B6 $5 \mathrm{mg}$, Vitamina B12 0,016 mg, Ácido Fólico 2,5 mg, Ácido Nicotínico 56 mg, Ácido Pantotênico 20 mg, Biotina 0,32 mg, Antioxidante 88 mg.

No sétimo dia de idade, oito aves por tratamento foram selecionadas aleatoriamente e eutanasiadas por deslocamento cervical. Em cada ave, o divertículo de Meckel foi localizado e, então, coletado um segmento jejunal de dois centrímetros anterior a essa estrutura anatômica com o objetivo de mensurar altura dos vilos $e$ as profundidades das criptas. Todas as amostras foram abertas longitudinalmente, lavadas com solução tampão fosfato $(0,1 \mathrm{M}, \mathrm{pH} 7,4)$ e fixadas em solução de Bouin por 24 horas. Em seguida os tecidos foram desidratados em série de concentração crescente de álcool, diafanizadas em xilol e incluídos em parafina. Foram realizados cortes histológicos com $5 \mu \mathrm{m}$ de espessura e corados com ácido periódico de Shiff (PAS). As análises de vilos e criptas foram feitas utilizando sistema 
analisador de imagens (Motic Image Plus 2.0) acopladas a um microscópio (Olympus BH2 Olympus América INC., NY, USA). Foram avaliados 30 vilos e 30 criptas de cada repetição, totalizando 540 leituras por variável analisada.

Os dados foram submetidos à análise de variância por meio da utilização do pacote estatístico SAEG (UFV, 2007) e, na presença de diferenças significativas $(P<0,05)$, as médias foram comparadas pelo teste de Duncan, ao nível de $5 \%$ de significância.

\section{RESULTADOS E DISCUSSÃO}

Os resultados apresentados na Tabela 2 mostram que, aos 7 dias, houve diferença significativa $(P>0,05)$ para altura de vilos. As vilosidades das aves alimentadas com a dieta contendo $\beta$-mananase (T3) foram maiores quando comparado ao grupo de aves alimentadas com a dieta basal com redução de $150 \mathrm{kcal} / \mathrm{kg}$ (T2).

As aves alimentadas com a dieta de energia reduzida (T2) e contendo a enzima $\beta$-mananase (T3), não diferiram significativamente $\quad(P>0,05)$ para profundidade de criptas em relação ao grupo consumindo a dieta basal (T1) (Tabela 2).

Para Jackson et al. (2004), a proliferação celular e manutenção da mucosa intestinal exigem uma alta demanda energética. Portanto, a adição da enzima $\beta$-mananase às dietas relaciona-se com o aumento na altura de vilos, justamente por proporcionar aumento na disponibilidade de nutrientes e de energia para renovação celular do intestino delgado, reduzindo a energia gasta na quebra dos alimentos por conseqüência da redução da viscosidade da digesta.

Tabela 2. Efeito da adição da enzima $\beta$-mananase sobre a altura de vilos e profundidade de criptas em peruas, aos 7 dias de idade.

\begin{tabular}{ccc}
\hline TRATAMENTOS & Altura de Vilo $(\boldsymbol{\mu m})$ & Profundidade de Cripta $(\boldsymbol{\mu m})$ \\
\hline Dieta Basal $(\mathrm{DB})$ & $631^{\mathrm{ab}}$ & 87 \\
DB $-150 \mathrm{kcal} / \mathrm{kg}$ & $610^{\mathrm{b}}$ & 85 \\
$\mathrm{DB}-150 \mathrm{kcal} / \mathrm{kg}+\beta$ mananase & $651^{\mathrm{a}}$ & 88 \\
\hline $\mathrm{P}$ & 0,021 & $\mathrm{NS}^{1}$ \\
CV $(\%)$ & 9,31 & 6,97
\end{tabular}

${ }^{1} \mathrm{NS}$ - não significativo.

Médias seguidas por letras minúsculas distintas, na coluna, diferem estatisticamente entre si pelo teste de Duncan (5\%).

O aumento na altura de vilos pode também estar relacionado ao fato da enzima $\beta$-mananase hidrolizar os $\beta$ mananos do farelo de soja em mananoligossacarídeos (MOS) (Huang et al., 2003), agentes tróficos que podem estimular o desenvolvimento da mucosa intestinal, acelerando o processo mitótico na região cripta-vilo, e assim aumentando o número de células e tamanho do vilo (Maiorka et al., 2002).

Aos 7 dias não foram observadas diferenças no consumo de ração entre as aves dos diferentes tratamentos (Tabela 3). No entanto, aos 21 dias as aves que consumiram ração com menor nível energético (T2 e T3) apresentaram um maior consumo $(P<0,05)$ em relação ao grupo consumindo ração sem redução energética. Segundo Richards e Proszkowiec-Weglarz (2007), as aves tendem a aumentar o consumo de ração de forma a compensar um reduzido nível energético da dieta. Essa diferença pode ser resultado não da adição da enzima às dietas, mas sim da grande habilidade das aves em regular 0 consumo a fim de manter seu crescimento, de acordo com o descrito por Leeson et al. (1996).

A suplementação da enzima $\beta$ mananase não afetou o consumo da 
ração quando comparada a dieta com redução energética e sem enzima. Esse resultado está de acordo com o encontrado por Odetallah et al. (2002), que não observaram um aumento significativo no consumo de ração comparando dois tipos de farelo de soja (com $44 \%$ e $48 \%$ de proteína bruta) em dietas de perus suplementados ou não com a enzima $\beta$-mananase. Da mesma forma, Zou et al. (2006), trabalhando com frangos na fase inicial (até três semanas de idade) não encontraram diferenças significativas para consumo de ração com a adição da enzima $\beta$ mananase.

Tabela 3. Efeito da adição da enzima $\beta$-mananase sobre o consumo de ração (CR), ganho de peso (GP) e conversão alimentar (CA) de peruas, aos 7 e aos 21 dias de idade.

Fase 1: de 1 a 7 dias

\begin{tabular}{cccc}
\hline TRATAMENTO & CR $(\mathbf{g})$ & GP $(\mathbf{g})$ & CA (g/g) \\
\hline Dieta Basal (DB) & 102,0 & 107,0 & $0,968^{\mathrm{a}}$ \\
DB $-150 \mathrm{kcal} / \mathrm{kg}$ & 107,0 & 108,0 & $1,005^{\mathrm{b}}$ \\
DB $-150 \mathrm{kcal} / \mathrm{kg}+\beta$ mananase & 108,0 & 106,0 & $1,051^{\mathrm{c}}$ \\
\hline $\mathrm{P}$ & $\mathrm{NS}$ & $\mathrm{NS}$ & 0,001 \\
CV $(\%)$ & 5,376 & 4,752 & 3,495 \\
\hline
\end{tabular}

\begin{tabular}{|c|c|c|c|}
\hline \multicolumn{4}{|c|}{ Período Total: de 1 a 21 dias } \\
\hline TRATAMENTO & CR $(g)$ & GP $(g)$ & $\mathrm{CA}(\mathrm{g} / \mathrm{g})$ \\
\hline Dieta Basal (DB) & $789,0^{b}$ & $599,0^{b}$ & 1,318 \\
\hline DB $-150 \mathrm{kcal} / \mathrm{kg}$ & $818,0^{a}$ & $598,0^{b}$ & 1,369 \\
\hline $\mathrm{DB}-150 \mathrm{kcal} / \mathrm{kg}+\beta$ mananase & $828,0^{a}$ & $611,0^{\mathrm{a}}$ & 1,356 \\
\hline $\mathrm{P}$ & 0,019 & 0,05 & NS \\
\hline CV (\%) & 3,207 & 1,887 & 3,194 \\
\hline
\end{tabular}

${ }^{1} \mathrm{NS}$ - não significativo.

Médias seguidas por letras minúsculas distintas, na coluna, diferem significativamente entre si pelo teste de Duncan $(P<0,05)$.

O ganho de peso no tratamento com adição da enzima $\beta$-mananase foi significativamente maior no período de 1 a 21 dias comparado aos demais tratamentos (Tabela 3). Apesar da diferença nutricional entre os tratamentos 1 e 2 (150 kcal), o ganho de peso desses tratamentos foram iguais $(P>0,05)$. Essa igualdade foi atingida devido ao maior consumo de ração no tratamento com menor nível energético.

Apesar do consumo de ração dos tratamentos 2 e 3 terem sido iguais, o ganho de peso do tratamento com a adição da $\beta$-mananase foi maior. Concordando com os dados encontrados no presente trabalho, Imran et al. (2014), ao avaliarem os efeitos da inclusão de $\beta$-mananase em dietas de frangos com níveis reduzidos de energia, concluíram que a enzima melhora significativamente o ganho de peso dos animais. Zou et al. (2006) investigando os efeitos da inclusão de $\beta$-mananase em dietas de frangos concluíram que a adição da enzima melhora o ganho de peso entre a quarta e a sexta semana de vida, não ocorrendo melhoras significativas nas três primeiras semanas. Os efeitos benéficos da $\beta$-mananase sobre 0 ganho de peso advem possívelmente da maior degradação dos $\beta$-mananos da dieta.

pintinhos, exigem maior energia metabolizável na ração nesta fase, devido à menor capacidade digestiva (Batal e Parson, 2002) e rápida taxa de 
crescimento. Em trabalho de Nascimento et al. (2004), por exemplo, avaliando três níveis de energia para pintinhos na fase pré-inicial (0 a 7 dias), os autores observaram que a conversão alimentar era melhorada na medida em que se aumentava a energia da dieta. No presente trabalho, os perus compensaram a alta exigência energética aumentando o consumo de ração, contudo a adição de $\beta$-mananase melhorou o ganho de peso, desta forma mantendo uma conversão alimentar similar as aves recebendo dieta basal.

Avaliando a inclusão da enzima $\beta$-mananase em dietas de frangos de corte, Latham et al. (2016) encontraram em média, uma melhora de $5,08 \%$ na conversão alimentar aos 14 dias de idade. Da mesma forma, em uma série de outros estudos foram observadas melhorias da conversão alimentar de frangos (McNaughton et al., 1998; Jackson et al., 2003; Zou et al., 2006; Ferreira et al., 2016) e perus (Odetallah et al., 2002), quando utilizada $\beta$ mananase, resultado de uma redução dos efeitos antinutricionais dos $\beta$ mananos.

\section{CONCLUSÕES}

$A$ adição da enzima $\beta$-mananase permite a redução dos níveis energéticos da dieta de peruas, sem afetar a altura de vilos e a profundidade de criptas aos 7 dias de idade. A redução nos níveis energéticos da dieta aumenta o consumo de ração em perus, porém a suplementação enzimática de $\beta$-mananase promove melhoria no ganho de peso das aves na fase inicial ( 1 aos 21 dias de idade), assim evitando o detrimento da conversão alimentar.

\section{REFERÊNCIAS}

BATAL, A.B.; PARSONS, C.M. Effects of age on nutrient digestibility in chicks fed different diets. Poultry Science, v.81, p.400-407, 2002.

CHANZY, H.; VUONG, R. Ultra structure and morphology of crystalline polysaccharides. In: ATKINS, E.D.T. Polysaccharides Topics in instructure and morphology. 1.ed. Bristol: $\mathrm{VCH}$ Publishers, 1985, Cap.2, p. 41-71.

CHOCT, M. Feed polysaccharides: nutritional roles and effect of enzymes. In: IV Congresso Latino Americano de Nutrição Animal - IV CLANA CBNA/AMENA. Estância de São Pedro, 2010.

DALE, N. Current status of feed enzymes for swine. Hemicell, Poultry and Swine Feed Enzyme. ChemGen Corp. Caithersburg, MD. 1997.

ELSENHANS, B.; SUFKE, U.; CASPARY, W. The influence of carbohydrate gelling agents on rat intestinal transporto $f$ monosaccharides and neutral amino acids in vitro. Clinical Science, v.59, p.373,1980.

FERREIRA, H.C.; HANNAS, M.I.; ALBINO, L.F.T.; ROSTAGNO, H.S.; NEME, R.; FARIA, B.D.; XAVIER, M.L.; RENÓ, L.N. Effect of the addition of $\beta$ mannanase on the performance, metabolizable energy, amino acid digestibility coefficients, and immune functions of broilers fed different nutritional levels. Poultry Science, v. 95, p. 1848-1857, 2016.

HSIAO, H.Y.; ANDERSON, D.M.; DALE, N.M. Levels of $\beta$-mannan in soybean meal. Poultry Science, v. 85 , p. $1430-$ 1432, 2006.

HUANG, X.W.; LIU, X.S.; XU, F.Q. The effect of $\beta$-mannanase on growth performance of growing pigs. Feed Research, p.29-31, 2003.

A conversão alimentar aos 21 dias das aves não foi diferente significativamente entre os tratamentos. Perus jovens, da mesma forma que os 
IMRAN, M.; PASHA, T. N.; SAIMA; AKRAM, M.; MEHMOOD, K.; SABIR, A. $J$. Effect of $\beta$-mannanase on broiles performance at different dietary energy levels. Global Veterinaria, v. 12, n. 5, p. 622-626, 2014.

JACKSON, M.E.; ANDERSON, D.M.; HSIAO, H.Y. et al. Beneficial effect of $\beta$ mananase feed enzyme on performance of chicks challenged with Eimeria $s p$. and Clostridium perfringens. Avian Diseases, v.47, p.759-763, 2003.

JACKSON, M.E.; GERONIAN, K.; KNOX, A. et al. A dose-response study with the feed enzyme $\beta$-mannanase in broilers provided with corn-soybean meal based diets in the absence of antibiotic. Poultry Science, v.83, p.1992-1996, 2004.

KRATZER, F.; RAJAGURER, R.; VOHRA, $P$. The effect of polysaccharides on energy utilization, $\mathrm{N}$ retention and fat absorption in chickens. Poultry Science, v.46, p.1489-1493, 1967.

LATHAM, R. E.; WILLIAMS, M.; SMITH, K.; STRINGFELLOW, K.; CLEMENTE, S.; BRISTER, R.; LEE, J. T. Effect of $\beta$ mannanase inclusion on growth performance, ileal digestible energy, and intestinal viscosity of male broilers fed a reduced-energy diet. Journal of Applied Poultry Research, v. 25, p. 4047, 2016.

LEESON, S.; CASTON, L.; SUMMERS, J.D. Broiler response to energy and protein dilution in the finisher diet. Poultry Science, v.75, n.4, p.522-528, 1996.

MAIORKA, A.; LECZNIESKI, J.; BARTELS, H.A. Efeito do nível energetico da Ração sobre 0 desempenho de frangos de corte de 1 a 7, 7 a 14 e 14 e 21 dias de idade. In: CONFERËNCIA APINCO DE CIÊNCIA E TECNOLOGIA AVÍCOLAS, São
Paulo. Anais... São Paulo: FACTA, p. 18, 1997.

MAIORKA, A.; BOLELI, I.C.; MACARI, M. Desenvolvimento e reparo da mucosa intestinal. In.: MACARI, M.; FURLAN, R.L.; GONZÁLES, E. (Eds) Fisiologia da digestão e absorção das aves. Campinas: Fundação Apinco de Ciência e Tecnologia Avícolas, Anais..., p. 113-124. 2002.

MCNAUGHTON, J.L.; HSIAO, H.; MADDENN, D.A. et al. Corn/soy/fat diets for broilers, $\beta$-manannase and improved feed conversion. Poultry Science, v.77 (Suppl. 1): 153 (Abstr.). 1998.

NASCIMENTO, A.H.; SILVA, J.H.V.; ALBINO, L.F.T. et al. Energia metabolizável e relação energia : proteína bruta nas fase pré-inicial e inicial de frangos de corte. Revista Brasileira de Zootecnia, v.33, n.4, p.911-918, 2004.

NUNES, C.S.; MALMLOF, K. Effects of guar gum and cellulose on glucose absorption, hormonal release, and hepatic metabolism in the pig. British Journal Nutrition, v.68, p.693-700, 1992.

ODETALLAH, H.N.; FERKET, P.R.; GRIMES, J.L. et al. Effect of mannanendo-1,4- $\beta$-mannosidase on the growth performance of turkeys fed diets containing 44 and $48 \%$ crude protein soybean meal. Poultry Science, v.81, p.1322-1331, 2002.

PENG, S.Y.; NORMAN, J.; CURTIN, G.; CORRIER, D. et al. Decreased mortality in Norman murine sarcoma in mice treated with the immonomodular, acemannan. Molecular Biotherapy, v.3 p.79-87, 1991.

RICHARDS, M. P.; PROSZKOWIECWEGLARZ, M. Mechanisms regulating feed intake, energy expenditure, and body weight in poultry. Poultry Science, v. 86, p. 1478-1490, 2007. 
ROSS, S.A.; DUNCAN, C.J.G.; PASCO, D.S. et al. Isolation of a galactomannan that enhances macrophage activation from the edible fungus Morchella esculenta. Journal of Agricultural and Food Chemistry, v.50, p.5683-5685, 2002.

SAEG, Sistema para Análises Estatísticas, Versão 9.1: Fundação Arthur Bernardes - UFV - Viçosa, 2007.

VERMA, S.V.S.; McNAB, J.M. Guar meal in diets for broiler chickens. British Poultry Science. 1982.

ZHANG, L.; TIZZARD, I.R. Activation of a mouse macrophage cell line by acemannan: the major carbohydrate fraction from aloe vera gel. Immunopharmacology, v.35, p.119128, 1996.

ZOU, X.T.; QIAO, X.J.; XU, Z.R. Effect of $\beta$-mannanase (Hemicell) on growth performance and immunity of broilers. Poultry Science, v.85, p.2176-2179, 2006. 